\title{
Streptococcus massiliensis in the human mouth: a phylogenetic approach for the inference of bacterial habitats
}

\author{
F. Póntigo' ${ }^{1}$ C. Silva ${ }^{1}$, M. Moraga ${ }^{1,2}$ and S.V. Flores ${ }^{1}$ \\ 1Departamento de Antropología, FACSO, Universidad de Chile, Santiago, Chile \\ ${ }^{2}$ Programa de Genética Humana, ICBM, Universidad de Chile, Santiago, Chile \\ Corresponding author: S.V. Flores \\ E-mail: sfloresc@uchile.cl
}

Genet. Mol. Res. 14 (4): 19184-19190 (2015)

Received August 15, 2015

Accepted October 26, 2015

Published December 29, 2015

DOI http://dx.doi.org/10.4238/2015.December.29.28

ABSTRACT. Streptococcus is a diverse bacterial lineage. Species of this genus occupy a myriad of environments inside humans and other animals. Despite the elucidation of several of these habitats, many remain to be identified. Here, we explore a methodological approach to reveal unknown bacterial environments. Specifically, we inferred the phylogeny of the Mitis group by analyzing the sequences of eight genes. In addition, information regarding habitat use of species belonging to this group was obtained from the scientific literature. The oral cavity emerged as a potential, previously unknown, environment of Streptococcus massiliensis. This phylogenybased prediction was confirmed by species-specific polymerase chain reaction (PCR) amplification. We propose employing a similar approach, i.e., use of bibliographic data and molecular phylogenetics as predictive methods, and species-specific PCR as confirmation, in order to reveal other unknown habitats in further bacterial taxa.

Key words: Streptococcus massiliensis; Microbiome; Phylogeny; Mitis group, $\mathrm{RecN}$ 


\section{INTRODUCTION}

The genus Streptococcus is a diverse lineage consisting of gram-positive, spherical, catalase-negative organisms, including many facultative anaerobes (Montes and GarcíaArenzana, 2007). This group inhabits a broad range of environments, not only as pathogens, but also as part of the normal microbiome of humans and other animals.

Based on 16S rRNA gene phylogenies, this genus has been separated into six species groups (Kawamura et al., 1995). Among them, the Mitis group comprises diverse species of significant clinical importance, including Streptococcus pneumoniae and S. sanguinis, the pathogens responsible for pneumonia and endocarditis, respectively. Current opinion suggests that this group contains at least 17 species (Kawamura et al., 1995). Recently, S. massiliensis, a new species discovered in a sample of human blood, was added (Glazunova et al., 2006).

In the current study, we analyzed the Mitis group phylogeny and, in combination with published data of known sample origins, used this information to infer unknown habitats. Finally, we tested for the presence of $S$. massiliensis in human mouths, since our preliminary phylogenetic analysis suggested the oral cavity as a previously unidentified habitat for this species.

\section{MATERIAL AND METHODS}

\section{Phylogenetic analyses}

Sequences of the following genes were retrieved from GenBank and used to infer the Mitis group phylogeny: superoxide dismutase (sodA; Poyart et al., 2002; Whatmore and Whiley, 2002), elongation factor Tu, RNA polymerase subunit $\beta$ (tuf and $r p o B$, respectively; Simmon et al., 2008), 16S rRNA (Kawamura et al., 1995), RNase P subunit $\beta$ (rnpB; Täpp et al., 2003), heat shock protein 40, DNA gyrase subunit B (dnaJ and gyrB, respectively; Itoh et al., 2006), and recombination protein N (recN; Glazunova et al., 2010; Table 1). The 17 species composing the Mitis group (Kawamura et al., 1995, 1999; Glazunova et al., 2006; Boggs et al., 2012) were included in our analyses. Their close phylogenetic relationship was corroborated in a new analysis using concatenated fragments of $\operatorname{recN}$ and $\operatorname{gyr} B$ genes (data not shown). Two outgroups belonging to the genus Lactococcus were used, namely $L$. lactis subsp lactis and $L$. lactis subsp cremoris.

Sequences were aligned using BioEdit version 7.0.9.0 (Hall, 1999) and alignments were checked and re-edited by eye. Nucleotide sequences were concatenated into a single supermatrix. Missing data were coded as such and incorporated into subsequent analyses. This "supermatrix" strategy has been shown to perform better than strategies involving the elimination of data or the use of non-concatenated matrices, particularly when Bayesian methods are used for phylogenetic inference (Wiens and Moen, 2008).

Molecular evolution models for nucleotide sequences were selected using the Akaike information criterion test, as implemented in the programs Modeltest (Posada and Crandall, 1998) and MrModeltest (Nylander, 2004). Bayesian inference was performed on the supermatrix using MrBayes version 3.0b4, specifying 4,000,000 generations and four independent chains.

Subsequently, known habitats for each of the 17 species were identified by searching the literature (Table 2) and the information gathered was mapped onto the phylogenetic tree. 
Table 1. List of Streptococcus and Lactococcus sequences retrieved from GenBank used in the phylogenetic analysis.

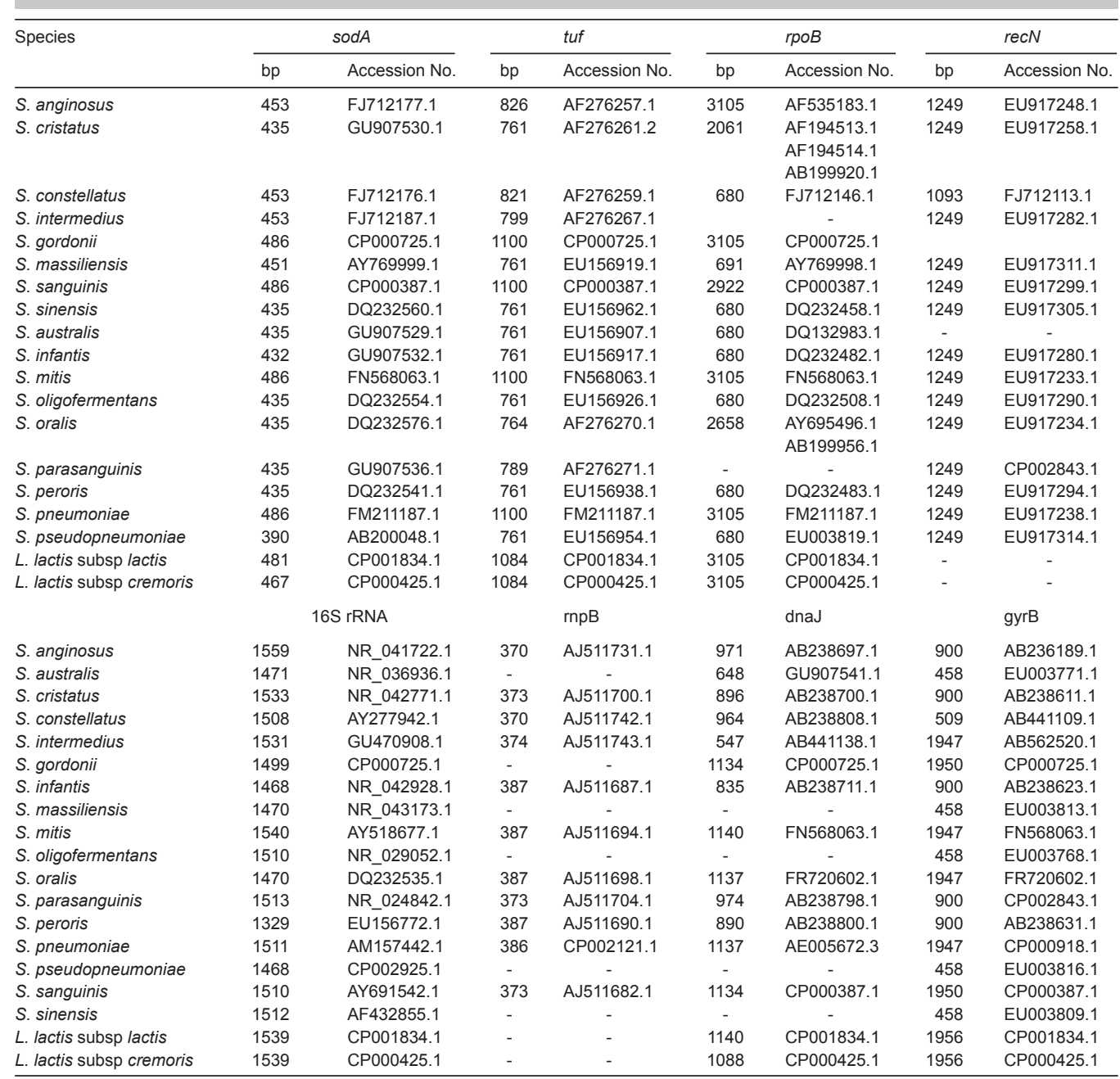

\section{Samples}

Saliva was collected from 29 volunteers. All participants signed an informed consent form, which prevents use of the data collected for purposes other than this research, and protects their confidentiality. This document was reviewed and approved by the Ethics Committee for Research in Social Science and Humanities (CEDEA) of the Faculty of Philosophy at the University of Chile. Two or three DNA extractions were carried out for each sample of saliva (Quinque et al., 2006).

\section{Polymerase chain reaction (PCR)}

Primers used to amplify a fragment of the recN gene were designed using Primer3 Input (Untergrasser et al., 2012) and a recent sequence for S. massiliensis (GenBank accession No. 
EU917311.1). This gene fragment was selected based on the high variability that it demonstrated in other species of the Mitis group in a preliminary analysis (Table 3).

\begin{tabular}{ll} 
Table 2. Habitats occupied by the Streptococcus and Lactococcus species included in this study. \\
\hline Species & Habitat \\
\hline S. anginosus & Oral cavity, gastrointestinal and urogenital tracts \\
S. australis & Oral cavity \\
S. cristatus & Oral cavity \\
S. constellatus & Oropharynx, respiratory tract \\
S. intermedius & Oral cavity, respiratory tract \\
S. gordonii & Oral cavity \\
S. infantis & Oral cavity, upper respiratory tract (humans) \\
S. massiliensis & Blood sample \\
S. mitis & Oral cavity \\
S. oligofermentans & Oral cavity \\
S. oralis & Oral cavity \\
S. parasanguinis & Oral cavity (humans) \\
S. peroris & Oral cavity (humans) \\
S. pneumoniae & Nasopharynx, oral cavity (humans), nasopharynx (pigs, cats, horses, dogs) \\
S. pseudopneumoniae & Phlegm (humans) \\
S. sanguinis & Oral cavity \\
S. sinensis & Oral cavity \\
L. lactis subsp lactis & Dairy products \\
L. lactis subsp cremoris & Dairy products \\
\hline & \\
\hline
\end{tabular}

Table 3. Proportion of variable sites in different gene fragments from species belonging to the Mitis species group.

\begin{tabular}{llr}
\hline Gene fragment & Variability & Proportion of variable sites \\
\hline$r p o B$ & $223 / 680$ & 0.3 \\
$\operatorname{sod} A$ & $220 / 486$ & 0.45 \\
$r e c N$ & $669 / 1258$ & 0.53 \\
\hline
\end{tabular}

Primer sequences and their respective melting temperatures were as follows: MassiF, 5'-CGA CTT GGA CGC GAT TAG CG-3', 56.27 C; and MassiR, 5'-TAC CTG CTC ATT GCC CTC GCG GTT-3', $62.53^{\circ} \mathrm{C}$. The amplified sequence fragment comprised nucleotide positions 634 to 1111 of the $\operatorname{rec} N$ gene.

In order to determinate the optimal annealing temperature for amplification, a thermal gradient PCR was performed, ranging from $55^{\circ}$ to $65^{\circ} \mathrm{C}$ in 12 intervals over 35 cycles, using two replicates per sample and a negative control for each temperature.

Seven successfully amplified products were submitted for direct sequencing to Macrogen Inc. (Seoul, Korea). BLAST (http://blast.ncbi.nlm.nih.gov/Blast.cgi) searches were performed in order to confirm the species-specific amplification expected from the primer design.

\section{RESULTS}

\section{Phylogenetic analysis}

Bayesian analysis resulted in a tree with high posterior probabilities for the majority of its internal nodes (Figure 1). Two well-defined subclades, namely the Mitis and Gordonii groups, are shown. Mapping of habitats onto the phylogeny revealed that the majority of the species under investigation inhabit the oral cavity. The species of particular interest in this study, S. massiliensis, was found to be basal to the subclade [(S. constellatus, S. intermedius), S. anginosus]. 


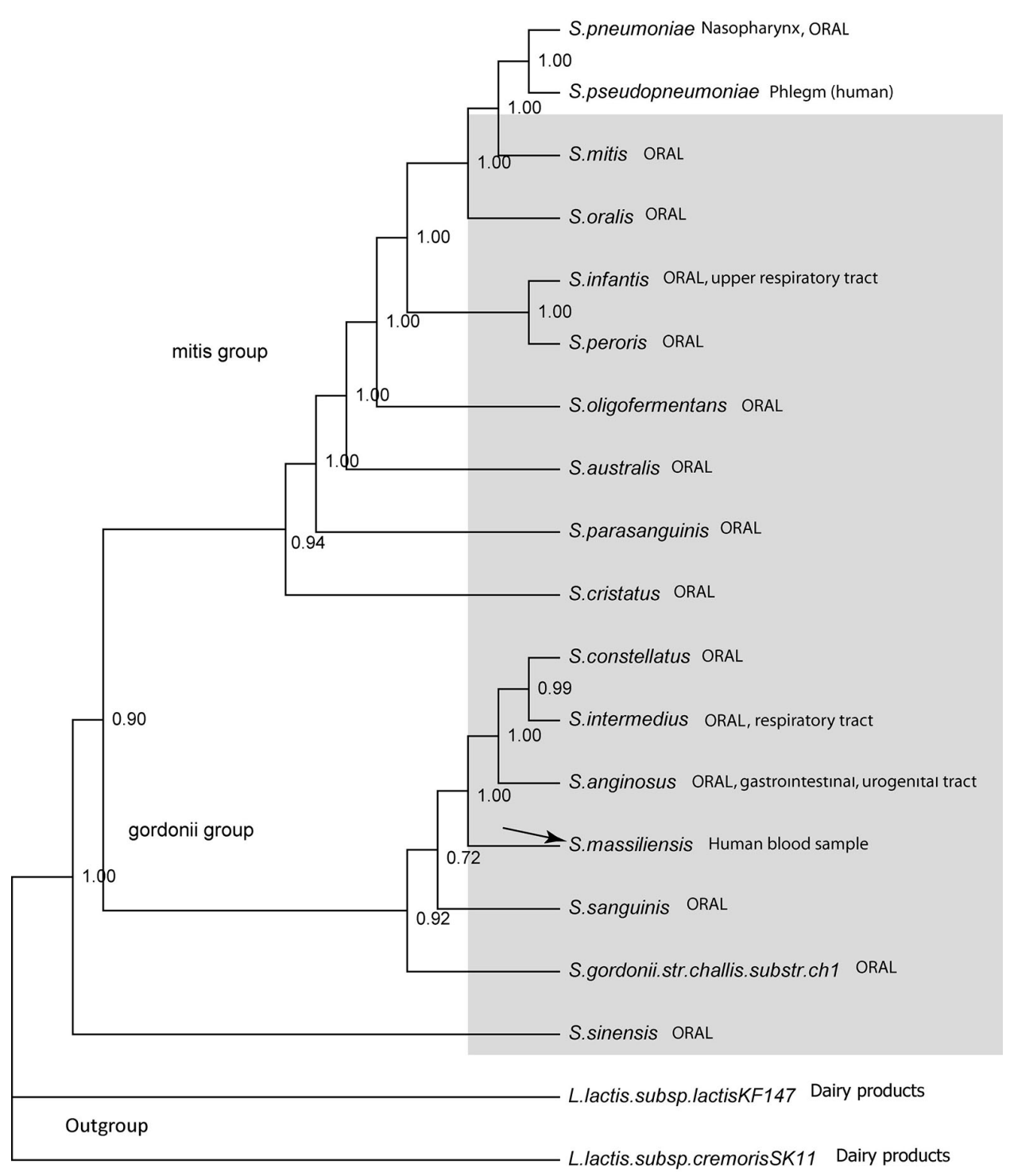

Figure 1. Majority-rule consensus tree obtained from a Bayesian analysis utilizing concatenated sequences from fragments of eight genes (16S rRNA, $r n p B, r p o B$, dnaJ, gyrB, sodA, tuf, and recN). Seventeen Streptococcus species were included, along with two Lactococcus species as outgroups. In addition, the habitat occupied by each species was mapped onto the tree according to information obtained from the literature. The general time-reversible + gamma + invariant sites nucleotide substitution model was used.

\section{PCR}

PCR was carried out on several samples using various numbers of cycles, as shown in Table 4. Optimal results were achieved with 40 cycles and an annealing temperature of $64.7^{\circ} \mathrm{C}$. 
Table 4. Results of polymerase chain reaction amplifications using different numbers of cycles.

\begin{tabular}{lcccc}
\hline & 35 cycles & 40 cycles & 45 cycles & 50 cycles \\
\hline Samples with successfully amplified products & 4 & 11 & 4 & 4 \\
Samples with non-specific products & 0 & 1 & 1 & 8 \\
Samples with non-amplified product & 25 & 13 & 14 & 13 \\
\hline
\end{tabular}

\section{DNA sequencing and analysis}

As shown in Figure 2, no differences were detected between the seven sequences obtained and the reference sequence (GenBank accession No. EU917311.1), indicating that the amplicons derived from S. massiliensis.

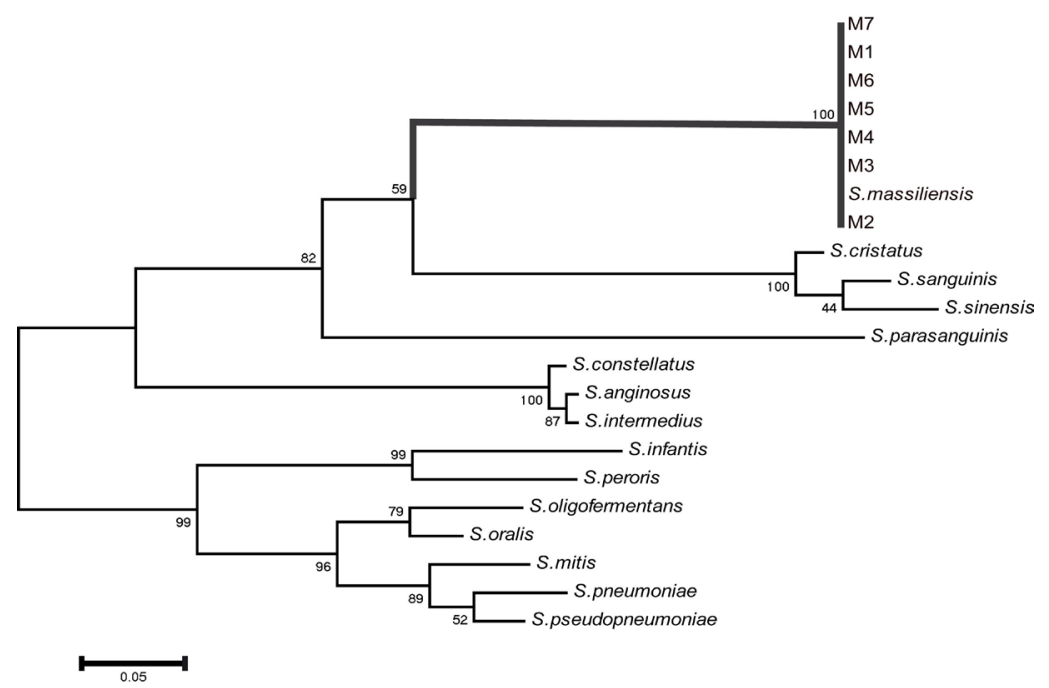

Figure 2. Electrophoresis of Streptococcus massiliensis polymerase chain reaction products ( $35 \mathrm{cycles}, 75 \mathrm{~V}, 75 \mathrm{~min}$ ). Lanes and their respective samples are labelled.

\section{DISCUSSION}

In the present study, we demonstrated that S. massiliensis, a Streptococcus species recently discovered in human blood, is a regular inhabitant of the human oral cavity, as predicted from habitatuse data and a phylogeny of the Mitis species group. Similar approaches could be employed to reveal unknown habitats occupied by other lineages of bacteria and Streptococcus species.

\section{Conflicts of interest}

The authors declare no conflict of interest.

\section{ACKNOWLEDGMENTS}

Research supported by the following grants: FONDECYT (\#1110461), FONDECYT (\#1140544); and Programa de Investigación Asociativa Conicyt, Anillo (\#ACT-096). 


\section{REFERENCES}

Boggs JM, South AH and Hughes AL (2012). Phylogenetic analysis supports horizontal gene transfer of L-amino acid oxidase gene in Streptococcus oligofermentans. Infect. Genet. Evol. 12: 1005-1009.

Glazunova OO, Raoult D and Roux V (2006). Streptococcus massiliensis sp. nov., isolated from a patient blood culture. Int. J. Syst. Evol. Microbiol. 56: 1127-1131.

Glazunova OO, Raoult D and Roux V (2010). Partial recN gene sequencing: a new tool for identification and phylogeny within the genus Streptococcus. Int. J. Syst. Evol. Microbiol. 60: 2140-2148.

Hall TA (1999). BioEdit: a user-friendly biological sequence alignment editor and analysis program for Windows 95/98/NT. Nucleic Acids Symposium Series, 41: 95-98.

Handley P, Coykendall A, Beighton D, Hardie JM, et al. (1991). Streptococcus crista sp. nov., a Viridans Streptococcus with tufted fibrils, isolated from the human oral cavity and throat. Int. J. Syst. Bacteriol. 41: 543-547.

Itoh Y, Kawamura Y, Kasai H, Shah MM, et al. (2006). dnaJ and gyrB gene sequence relationship among species and strains of genus Streptococcus. Syst. Appl. Microbiol. 29: 368-374.

Kawamura Y, Hou XG, Sultana F, Miura H, et al. (1995). Determination of $16 \mathrm{~S}$ rRNA sequences of Streptococcus mitis and Streptococcus gordonii and phylogenetic relationships among members of the genus Streptococcus. Int. J. Syst. Bacteriol. 45: 406-408.

Kawamura Y, Whiley RA, Shu SE, Ezaki T, et al. (1999). Genetic approaches to the identification of the mitis group within the genus Streptococcus. Microbiology 145: 2605-2613.

Montes M and García-Arenzana JM (2007). Género Streptococcus: una revisión práctica para el laboratorio de microbiología Enferm. Infecc. Microbiol. Clin. 25 (Suppl 3): 14-20.

Nylander JAA (2004). 'MrModeltest v2', Computer Program, Evolutionary Biology Centre, Uppsala University.

Posada D and Crandall KA (1998). MODELTEST: testing the model of DNA substitution. Bioinformatics 14: 817-818.

Poyart C, Quesne G and Trieu-Cuot P (2002). Taxonomic dissection of the Streptococcus bovis group by analysis of manganese-dependent superoxide dismutase gene $(\operatorname{sod} A)$ sequences: reclassification of 'Streptococcus infantarius subsp. coli' as Streptococcus lutetiensis sp. nov. and of Streptococcus bovis biotype 11.2 as Streptococcus pasteurianus sp. nov. Int. J. Syst. Evol. Microbiol. 52: 1247-1255.

Quinque D, Kittler R, Kayser M, Stoneking M, et al. (2006). Evaluation of saliva as a source of human DNA for population and association studies. Anal. Biochem. 353: 272-277.

Simmon KE, Hall L, Woods CW, Marco F, et al. (2008). Phylogenetic analysis of Viridans group Streptococci causing Endocarditis. J. Clin. Microbiol. 46: 3087-3090.

Täpp J, Thollesson M and Herrmann B (2003). Phylogenetic relationships and genotyping of the genus Streptococcus by sequence determination of the RNase P RNA gene, rnpB. Int. J. Syst. Evol. Microbiol. 53: 1861-1871.

Untergrasser A, Cutcutache I, Koressaar T, Ye J, et al. (2012). Primer3 - new capabilities and interfaces. Nucleic Acids Res. 40: e115.

Whatmore AM and Whiley RA (2002). Re-evaluation of the taxonomic position of Streptococcus ferus. Int. J. Syst. Evol. Microbiol. 52: 1783-1787.

Wiens JJ and Moen DS (2008). Missing data and the accuracy of Bayesian phylogenetics. J. Syst. Evol. 46: 307-314. 